\title{
A Case of Listeria monocytogenes ST-219 Meningo-Encephalitis
}

\author{
Giovanni Sotgiu ${ }^{1,+}{ }^{\mathbb{C}}$, Narcisa Muresu ${ }^{2, *, \dagger}$, Marco Dettori ${ }^{1, *} \mathbb{0}$, Erica Mura ${ }^{1}$, Andrea Cossu ${ }^{1}$, \\ Maria Dolores Masia ${ }^{1}\left[\begin{array}{l}\text {, Paola Murgia } \\ \end{array}\right.$ \\ Christian Scarano ${ }^{5}$, Carlo Spanu ${ }^{5}$ and Andrea Piana ${ }^{1}$ (D) \\ 1 Department of Medical, Surgical and Experimental Sciences, University of Sassari, 07100 Sassari, Italy; \\ gsotgiu@uniss.it (G.S.); eri.mura@tiscali.it (E.M.); andreacossu@uniss.it (A.C.); mdmasia@uniss.it (M.D.M.); \\ piana@uniss.it (A.P.) \\ 2 Department of Biomedical Sciences, University of Sassari, 07100 Sassari, Italy; \\ 3 Intensive Unit Care, “SS Annunziata” Hospital, 07100 Sassari, Italy; paolamurgia77@tiscali.it \\ 4 Department of Medicine and Surgery, University of Milano-Bicocca, 20126 Monza, Italy; cocuzza@unimib.it \\ 5 Department of Veterinary Medicine, University of Sassari, 07100 Sassari, Italy; desantis@uniss.it (E.P.L.D.S.); \\ scarano@uniss.it (C.S.); cspanu@uniss.it (C.S.) \\ * Correspondence: narcisamuresu@outlook.com (N.M.); madettori@uniss.it; (M.D.); \\ Tel.: +39-079-229-091 (N.M); +39-079-228-467 (M.D.) \\ + Equally contributed.
}

Received: 20 November 2018; Accepted: 18 December 2018; Published: 20 December 2018

\begin{abstract}
Listeriosis is a foodborne disease characterized by high hospitalization and fatality rates, especially in vulnerable groups including elderly subjects, pregnant women, etc. We report on the first case of Listeria monocytogenes ST-219 meningo-encephalitis in a woman aged 83 years. An epidemiological and molecular investigation was performed to detect the source of infection and the virulence factors associated with L. monocytogenes invasiveness in this patient. All environmentaland clinical-associated isolates were found to belong to serotype $4 \mathrm{~b}$ and ST-219 as well as possessing $a c t A, \operatorname{prf} A, h l y A$, and $r r n$ virulence genes. Antibiotic susceptibility testing also detected resistance to cotrimoxazole, clindamycin, erythromycin, and oxacillin in these isolates. Conventional and molecular surveillance of listeriosis cases, based on the systematic assessment of spatio-temporal trends, virulence genes, and antimicrobial susceptibility testing patterns, are key to preventing and controlling the emergence and spread of L. monocytogenes strains, including hypervirulent clones.
\end{abstract}

Keywords: listeriosis; ST-219; virulence factors; foodborne infection

\section{Introduction}

Listeriosis, one of the most important foodborne infectious diseases, is caused by Listeria monocytogenes, which is a facultatively intracellular Gram-positive microorganism. Listeriosisis a clinical and public health issue, associated with high hospitalization and fatality (i.e., 30\%) rates, particularly in vulnerable groups, such as the elderly, pregnant women, newborns, and immunocompromised patients [1]. In the United States, listeriosis shows a low estimated annual incidence rate (1600 infections) in comparison with high hospitalization and mortality rates (1400 and 250 cases, respectively) [2]. In adults aged 65 years or older and pregnant women, the annual incidence rate was 1.3 and 3.0 cases per 100,000 population, respectively [3].

Its epidemiological burden can be significant owing to the broad L. monocytogenes environmental distribution. The bacteria's ability to survive in several stress conditions (e.g., low temperature) favors its growth in refrigerated food, such as cheese, raw milk, vegetables, smoked fish, and ready-to-eat 
meats [4]. The formation of biofilms can help increase its resistance to stress conditions (e.g., biocides and low and high temperature). The biofilm structure favors antimicrobial and resistance removal owing to its composition based on a matrix of extra-cellular polymeric substances.

Gastrointestinal listeriosis, the most frequent clinical form, can be complicated by sepsis, meningo-encephalitis, spontaneous abortion, or death [5]. Bacterial invasiveness has been partially explained by in vitro and ex vivo studies. Several hypotheses on host, Listeria spp., and environmental factors have been evaluated. In particular, L. monocytogenes shows virulence factors promoting intracellular survival and replication, escape from immune system, and cell-to-cell spread [6]. Expression of virulence genes can be regulated by the primary regulator Positive Regulatory factor A (PrfA), which activates a gene cluster involved in phagosomal lysis, polymerization of actin filaments, and human invasiveness [7].

Out of 13 L. monocytogenes serotypes, the majority (95\%) of human cases are caused by serovars $1 / 2 a, 1 / 2 b, 1 / 2 c$, and $4 b$ [8]. Virulence factors have been found in strains isolated from human cases but not in animal specimens [9].

The worldwide increased reporting of listeriosis cases has been explained by pathogen(e.g., virulence factors and antibiotic-resistance mechanisms) and host-related (e.g., elderly susceptible patients, high prevalence of chronic medical conditions) factors. In particular, an increasing incidence trend has been described in European countries in 2011-2014 [10]. However, the higher sensitivity of bacteriological diagnostic methods, following the implementation of rapid molecular tools, has contributed to a higher diagnosis and reporting rate [4].

Recent reports highlighted an increased proportion of antimicrobial resistant strains [11] after the first isolation of multidrug-resistant strains in 1988 [12,13]. Gene similarity conferring partial or missing drug susceptibility between Listeria spp., Enterococcus, and Streptococcus, suggests a horizontal transfer of mobile genetic elements and plasmids [11].

Control and prevention of foodborne cases requires an active systematic monitoring and surveillance system, which has been implemented in several high-income countries. In Italy, regional healthcare systems implemented and scaled-up surveillance and notification programs, aimed to control and prevent outbreak episodes associated with food-processing activities. In Sardinia, Italy, a surveillance program was funded and implemented, named "Strategies of active surveillance and networking of L. monocytogenes infections", promoted by the Sardinian Region [14] to prevent human, animal, and environmental transmission.

Herein, we describe a severe case of L. monocytogenes infection in an elderly Italian patient and the following preventative and control interventions, as well as its molecular profile, to better understand the role played by virulence factors in invasive disease.

\section{Case Presentation}

Ethical approval and informed consent for this study was unnecessary according to the Italian legislation concerning the guidelines for the performance of observational studies (G.U. n. 76. 31-3-2008).

In January 2018, an 83-year-old female patient with type II diabetes, hypertension, and overweight, and aphasia and two-day high fever $\left(39.2^{\circ} \mathrm{C}\right)$ was initially admitted to the internal medicine department of the University Hospital of Sassari, Italy. After her physical exam, she was immediately transferred to the Intensive Care Unit of the same hospital with a clinical suspicion of meningitis, confirmed by the magnetic resonance imaging findings. Blood, respiratory, urine, and cerebrospinal fluid (CSF) specimens were collected for chemical and bacteriological (both conventional and molecular) analyses.

High protein $(>340 \mathrm{mg} / \mathrm{dL})$, low glucose $(33 \mathrm{mg} / \mathrm{dL})$, and pleocytosis ( $>70 \%$ mononuclear cells) were found in CSF. L. monocytogenes was diagnosed in blood and CSF cultures using conventional and molecular techniques. In particular, the Vitek-2 System (BioMèrieux, Marcy l'Etoile, France) was used for identification, and antibiotic susceptibility was tested using Kirby-Bauer disc diffusion method following the Clinical and Laboratory Standards Institute (CLSI) guidelines. The extraction 
of bacterial chromosomal DNA was performed using QIAamp DNA Mini kit from blood and body fluids (QIAGEN cat. n. 51304). Molecular identification was carried out by real-time polymerase chain reaction (RT-PCR; EuSepScreen ${ }^{\circledR}$ Lattanti kit, Eurospital cod. 9144). Drug susceptibility testing showed resistance to cotrimoxazole, clindamycin, erythromycin, and oxacillin (Table 1).

Table 1. Drug susceptibility testing of the human Listeria monocytogenes isolate. Clinical and Laboratory Standards Institute (CLSI) 2004 Performance standards for antimicrobial susceptibility testing; 14th informational supplement (Wayne, PA, USA) Vol 24, No. 1, M100-S14.

\begin{tabular}{ccc}
\hline Antibiotic & Susceptibility & Disc Content $(\boldsymbol{\mu g})$ \\
\hline Ampicillin & Susceptible & 10 \\
Chloramphenicol & Susceptible & 30 \\
Ciprofloxacin & Susceptible & 5 \\
Clindamycin & Resistant & 2 \\
Erythromycin & Resistant & 15 \\
Gentamicin & Susceptible & 10 \\
Imipenem & Susceptible & 10 \\
Oxacillin & Resistant & 1 \\
Penicillin & Susceptible & $10 \mathrm{U}$ \\
Tetracycline & Susceptible & 30 \\
Vancomycin & Resistant & $1.25 / 23.75$ \\
Trimethoprim/Sulfamethoxazole & Susceptible & 30 \\
\hline
\end{tabular}

Infectious diseases specialists recommended a 3-week regimen of meropenem $(2 \mathrm{~g}$ thrice per day) $[15,16]$. After two days of treatment, fever decreased but severe neurological sequalae occurred (e.g., lack of consciousness, muscular hypotonia, and ipoasthenia). After 44 days of ICU stay, the patient was transferred out to the medicine ward in stable clinical condition and, then was discharged with a rehabilitation program prescribed to achieve a neurological recovery.

Following the standards described in the local protocol, an epidemiological investigation was started to detect any environmental sources of the infection [17]. A total of 25 samples were collected from food stored in (e.g., mortadella and cheese) and surfaces of the fridge located in the patient's house. All of them were positive for L. monocytogenes.

Detection of virulence genes (actA, prfA, $h l y A$, and $r r n$ ) (Figure 1) and serotyping (Figure 2) was performed on all L. monocytogenes isolates found in food, environmental surfaces, and biological samples using a multiplex PCR $[8,18]$. In particular, serotyping was carried out amplifying Imo0737, lmo1118, ORF2819, and ORF2110 sequences, with prs gene as positive control. All virulence genes were found in the isolates and the only serotype $4 \mathrm{~b}$ was diagnosed in all specimens.

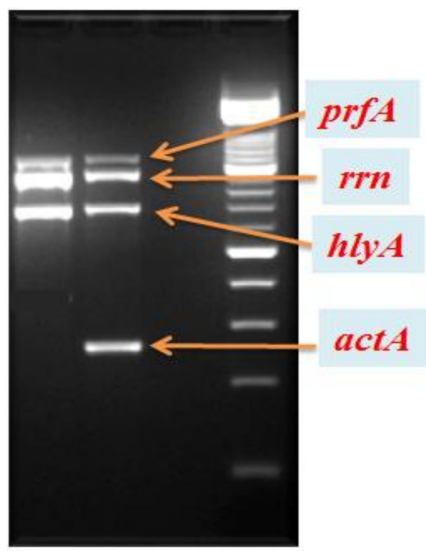

Figure 1. Polymerase chain reaction (PCR)-based virulence genes of L. monocytogenes strains isolated from food, environmental surfaces, and biological specimens. 


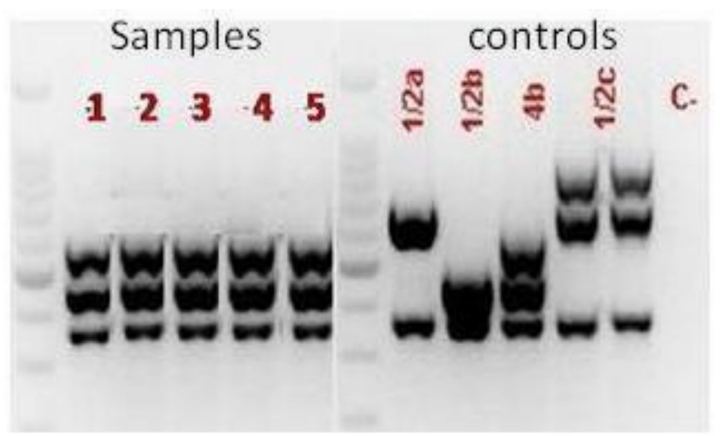

Figure 2. PCR-based serotyping of L. monocytogenes strains isolated from food, environmental surfaces, and biological specimens.

Isolates were compared using Pulse Field Gel Electrophoresis (PFGE) [19]. They were deemed clonally related if the Dice coefficient was $>80 \%$, whereas patterns with indistinguishable PFGE banding patterns (i.e., similarity coefficient $>97 \%$ ) were considered to belong to the same subtype [20]. Only profiles of the same Pulse-type were found (Figure 3).

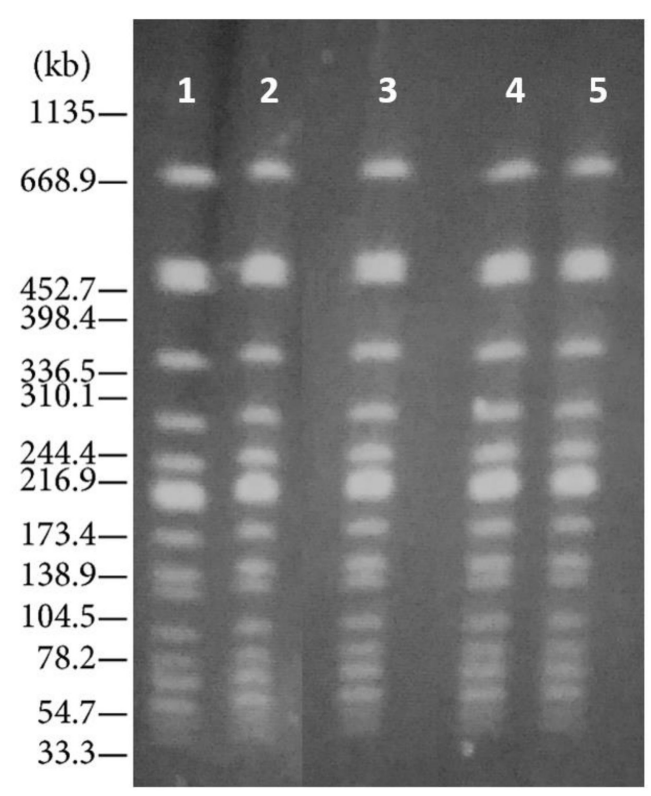

Figure 3. Pulse Field Gel Electrophoresis of L. monocytogenes isolates based on the use of the restriction enzyme ApaI. Line 1= Human isolate; Lines 2 and 3= Foodborne isolates; Lines 4 and 5= Environmental isolates. Salmonella branderup H9812: Molecular marker.

Multi Locus Sequence Type was completed following the Pasteur Institute protocol [21]. The internal fragments of seven L. monocytogenes housekeeping genes (i.e., gapA, infB, $m d h$, pgi, phoE, rрoB and ton $B$ ) were sequenced using Bioedit software (Ibis biosciences, Carlsbad, $C A$ ) to assess similarity and compatibility. Only the Sequence Type (ST)-219 was found.

\section{Discussion}

Despite considerable advances in food safety and control, listeriosis remains a serious public health issue with high fatality and hospitalization rates in vulnerable population groups [9]. The European Centre for Diseases Control and Prevention estimated 2502 cases in 2017, of which 67\% occurred in individuals aged more than 65 years old. About $75 \%$ of deaths occurred in the elderly, with a hospitalization rate above $98 \%$ [22]. 
This case report describes the first human case of listeriosis caused by the hypervirulent strain LM-ST-219, which contaminated environmental surfaces and food as proven by the identical molecular profile of the selected isolates.

Previous studies described hyper-and hypo-virulent clones of L. monocytogenes mainly associated with human and animal cases, respectively. The dichotomous incidence of serotypes in different beings is associated with a heterogeneous clonal complexity and expression of genes encoding for virulence factors [23].

Hypervirulent clones of L. monocytogenes have been shown to exhibit tropism to the central nervous system (CNS) and fetal placenta. ST-219 belongs to Clonal-Complex 4 (CC4), which is usually prevalent in cases of human listeriosis and in non-immunocompromised patients with comorbidities.

Maury et al. [24] reported a cluster of six hypervirulent genes (i.e., Listeria pathogenicity Island-4) encoding the putative cellobiose-family associated with CC4 and symptomatic human listeriosis, whereas they were not found in food-associated clones. All isolates we described in our case-report were CC4, i.e., hypervirulent. Detection of virulence factors in our case confirmed a relationship between L. monocytogenes invasiveness and prfA cluster genes [25].

Four out of 13 serotypes are strongly associated with human listeriosis and are grouped in the Lineage I [26]. Serotype $4 \mathrm{~b}$, described in our case report, has been frequently found in human cases and foods, although recent reports showed an increasing incidence of the animal serotype 1/2a and 3a in humans [27]. Specific serotypes are prevalent in some foods and environments; changes in human habits can increase the risk of acquiring serotypes whose incidence has been lowest in the recent past. In particular, several reports highlighted the threat of ready-to-eat foods (e.g., salmon carpaccio, marinated seafood salads, etc.), exposed to mild treatment during their preparation, then at risk of contamination, and frequently purchased by several population groups [28]. The long shelf-life of some products favor the L. monocytogenes cross-transmission, as proved in a Finnish 3a serotype-related outbreak linked to the distribution of contaminated butter [29].

Resistance to trimethoprim/sulfamethoxazole (a second-line drug in patients to penicillin) and other antibiotics in our isolates raise the issue of emerging antimicrobial resistance in L. monocytogenes strains [11]. The increasing spread of drug-resistant strains and virulence factors associated with specific serotypes may be play a pathogenic role that should be prevented to decrease L. monocytogenes fatality and hospitalization rate.

\section{Conclusions}

Our study highlights the importance of safe food handling and storage, particularly when highest risk persons (including elderly people) are exposed to contaminated food. A comprehensive surveillance and control program, as well as etiological distribution of hypervirulent strains in humans and animals, is needed to assess epidemiological changes (e.g., temporal and geographical trends). More attention should be paid to molecular and cellular mechanisms implemented by L. monocytogenes to increase its survival; in particular, the role of biofilm should not be underestimated when preventative measures are designed and planned. For instance, in the food industry, the pathogenetic role of this complex structure in the resistance to antimicrobials clearly proven, as well as in the transmission and spread of microbial strains detached from the upper part of the biofilm. In our case, the epidemiological association between isolates found in the refrigerator and detected in clinical specimens might have been underpinned by the formation of biofilm structures, which preserved colonies in stress conditions and favored their persistence [30]. Policies on appropriate cleaning systems should be implemented and scaled-up for processing environmental surfaces and equipment (e.g., bends in pipes, rubber seals, conveyor belts, glasses, etc.), as well as for food [31].

New guidelines and formal rules are needed to improve the management of antimicrobials in different fields, from the food processing chain to animal feeding and human therapies. Global commitment could hinder the emergence and spread of multi-drug resistant microorganisms, 
including hypervirulent strains of L. monocytogenes whose transmission could be fatal in vulnerable population groups.

Author Contributions: Conceptualization, G.S., N.M., A.P.; Data curation, G.S., N.M., A.P.; Formal analysis, G.S., N.M., M.D., M.D.M., E.M., P.M., A.C., C.C., E.P.L.D.S., C.S., A.P.; Investigation, G.S., N.M., M.D., M.D.M., C.C., E.M., P.M., A.C., E.P.L.D.S., C.S., A.P.; Methodology, G.S., N.M., M.D., M.D.M., E.M., P.M., A.C., E.P.L.D.S, C.C., C.S., A.P.; Supervision, G.S., N.M., A.P.; Writing—original draft, G.S., N.M., A.P.; Writing—review\& editing, G.S., N.M., M.D., M.D.M., E.M., P.M., A.C., C.C., E.P.L.D.S., C.S., A.P.

Conflicts of Interest: The authors declare no conflict of interest.

Ethics Approval: Ethical approval and informed consent for this study was unnecessary according to the Italian legislation concerning the guidelines for the performance of observational studies (G.U. n. 76. 31-3-2008).

\section{References}

1. Scallan, E.; Hoekstra, R.M.; Mahon, B.E.; Jones, T.F.; Griffin, P.M. An assessment of the human health impact of seven leading foodborne pathogens in the United States using disability adjusted life years. Epidemiol. Infect. 2015, 143, 2795-2804. [CrossRef] [PubMed]

2. Scallan, E.; Hoekstra, R.M.; Angulo, F.J.; Tauxe, R.V.; Widdowson, M.A.; Roy, S.L.; Jones, J.L.; Griffin, P.M. Foodborne illness acquired in the United States-Major pathogens. Emerg. Infect. Dis. 2011, 17, 7-15. [CrossRef] [PubMed]

3. Centers for Disease Control and Prevention. Vital Signs: Listeria Illnesses, Deaths, and Outbreaks-United States, 2009-2011. Morb. Mortal. Wkly. Rep. 2013, 62, 448-452.

4. Allerberger, F.; Wagner, M. Listeriosis: A resurgent foodborne infection. Clin. Microbiol. Infect. 2010, 16, 16-23. [CrossRef]

5. Van Walle, I.; Björkman, J.T.; Cormican, M.; Dallman, T.; Mossong, J.; Moura, A.; Pietzka, A.; Ruppitsch, W.; Takkinen, J. European Listeria WGS Typing Group. Retrospective validation of whole genome sequencing-enhanced surveillance of listeriosis in Europe, 2010 to 2015. Euro Surveill. 2018, 23, 1700798. [CrossRef] [PubMed]

6. Camejo, A.; Carvalho, F.; Reis, O.; Leitão, E.; Sousa, S.; Cabanes, D. The arsenal of virulence factors deployed by Listeria monocytogenes to promote its cell infection cycle. Virulence 2011, 2, 379-394. [CrossRef] [PubMed]

7. Portnoy, D.A.; Chakraborty, T.; Goebel, W.; Cossart, P. Molecular Determinants of Listeria monocytogenes Pathogenesis. Infect. Immun. 1992, 60, 1263-1267. [PubMed]

8. Doumith, M.; Buchrieser, C.; Glaser, P.; Jacquet, C.; Martin, P. Differentiation of the major Listeria monocytogenes serovars by multiplex PCR. J. Clin. Microbiol. 2004, 42, 3819-3822. [CrossRef]

9. Buchanan, R.L.; Gorris, L.G.M.; Hayman, M.M.; Jackson, T.C.; Whiting, R.C. A review of Listeria monocytogenes: An update on outbreaks, virulence, dose-response, ecology, and risk assessments. Food Control 2017, 75, 1-13. [CrossRef]

10. European Centre for Disease Prevention and Control. Listeriosis. In Annual Epidemiological Report for 2015; ECDC: Stockholm, Sweden, 2018; Available online: https:/ / ecdc.europa.eu/sites / portal/files / documents / AER_for_2016-listeriosis.pdf (accessed on 19 November 2018).

11. Charpentier, E.; Courvalin, P. Antibiotic Resistance in Listeria spp. Antimicrob. Agents Chemother. 1999, 43, 2103-2108. [CrossRef]

12. Hadorn, K.; Hachler, H.; Schaffner, A.; Kayser, F.H. Genetic characterization of plasmid-encoded multiple antibiotic resistance in a strain of Listeria monocytogenes causing endocarditis. Eur. J. Clin. Microbiol. Infect. Dis. 1993, 12, 928-937. [CrossRef]

13. Quentin, C.; Thibaut, M.C.; Horovitz, J.; Bebear, C. Multiresistant strain of Listeria monocytogenes in septic abortion. Lancet 1990, 336, 375. [CrossRef]

14. Strategie di Sorveglianza attiva e networking per il controllo delle infezioni da L. monocytogenes. Available online: www.listeriaweb.uniss.it/index.php/progetto (accessed on 19 November 2018).

15. Van de Beek, D.; Cabellos, C.; Dzupova, O.; Esposito, S.; Klein, M.; Kloek, A.T.; Leib, S.L.; Mourvillier, B.; Ostergaard, C.; Pagliano, P.; et al. ESCMID guideline: Diagnosis and treatment of acute bacterial meningitis. Clin. Microbiol. Infect. 2016, 22, S37-S62. [CrossRef] 
16. Piana, A.; Are, R.; Orrù, M.; Saba, F.; Dettori, M.; Maida, I.; Sotgiu, G.; Rais, C.; Mura, M.S. Listeria monocytogenes meningoencephalitis: Molecular methods for diagnosis and for monitoring the response to chemotherapy. Ital. J. Public Health 2005, 2, 29-34.

17. ISO 11290-1:1996/Amd 1:2004. Microbiology of Food and Animal Feeding Stuffs Horizontal Method for the Detection and Enumeration of Listeria monocytogenes. Part 1; International Organization for Standardization: Geneva, Switzerland, 2017.

18. Mureddu, A.; Mazza, R.; Fois, F.; Meloni, D.; Bacciu, R.; Piras, F.; Mazzette, R. Listeria monocytogenes persistence in ready-to-eat sausages and in processing plants. Ital. J. Food Saf. 2014, 3, 1697. [CrossRef] [PubMed]

19. Centers of Disease Control and Prevention. Standard Operating Procedure for PulseNet PFGE of Listeria monocytogenes; Centers for Disease Control and Prevention: Atlanta, GA, USA, 2013. Available online: http:/ / www.cdc.gov / pulsenet/PDF/listeria-pfge-protocol-508c.pdf (accessed on 19 November 2018).

20. Tenover, F.C.; Arbeit, R.D.; Goering, R.V.; Mickelsen, P.A.; Murray, B.E.; Persing, D.H.; Swaminathan, B. Interpreting chromosomal DNA restriction patterns produced by pulsed-field gel electrophoresis: Criteria for bacterial strain typing. J. Clin. Microbiol. 1995, 33, 2233-2339.

21. Primers Used for Amplification and Sequencing (MLST). Available online: http://bigsdb.pasteur.fr/listeria/ listeria.html (accessed on 19 November 2018).

22. Surveillance Atlas of Infectious Diseases (ECDC). Available online: www.ecdc.europa.eu/en/surveillanceatlas-infectious-diseases- (accessed on 19 November 2018).

23. Maury, M.M.; Chenal-Francisque, V.; Bracq-Dieye, H.; Han, L.; Leclercq, A.; Vales, G.; Moura, A.; Gouin, E.; Scortti, M.; Disson, O.; et al. Spontaneous loss of virulence in natural populations of Listeria monocytogenes. Infect Immun. 2017, 85, e00541-17. [CrossRef] [PubMed]

24. Maury, M.M.; Tsai, Y.; Charlier, C.; Touchon, M.; Chenal-Francisque, V.; Leclercq, A.; Criscuolo, A.; Gaultier, C.; Roussel, S.; Brisabois, A.; et al. Uncovering Listeria monocytogenes hypervirulence by harnessing its biodiversity. Nat. Genet. 2016, 48, 308-313. [CrossRef] [PubMed]

25. Drevets, D.A. Listeria monocytogenes. Virulence factors that stimulate endothelial cells. Infect. Immun. 1998, 66, 232-238.

26. McLauchlin, J. Distribution of serovars of Listeria monocytogenes isolated from different categories of patients with listeriosis. Eur. J. Clin. Microbiol. Infect. Dis. 1990, 9, 210-213. [CrossRef]

27. Pontello, M.; Guaita, A.; Sala, G.; Cipolla, M.; Gattuso, A.; Sonnessa, M.; Gianfranceschi, M.V. Listeria monocytogenes serotypes in human infections (Italy, 2000-2010). Ann. Ist. Super. Sanita 2012, 48, 146-150. [CrossRef] [PubMed]

28. Gambarin, P.; Magnabosco, C.; Losio, M.N.; Pavoni, E.; Gattuso, A.; Arcangeli, G.; Favretti, M. Listeria monocytogenes in Ready-to-Eat Seafood and Potential Hazards for the Consumers. Int. J. Microbiol. 2012, 2012, 497635. [CrossRef]

29. Maijala, R.; Lyytikäinen, O.; Autio, T.; Aalto, T.; Haavisto, L.; Honkanen-Buzalski, T. Exposure of Listeria monocytogenes within an epidemic caused by butter in Finland. Int. J. Food Microbiol. 2001, 70, 97-109. [CrossRef]

30. Colagiorgi, A.; Bruini, I.; Di Ciccio, P.A.; Zanardi, E.; Ghidini, S.; Ianieri, A. Listeria monocytogenes Biofilms in the Wonderland of Food Industry. Pathogens 2017, 6, 41. [CrossRef] [PubMed]

31. Di Ciccio, P.; Conter, M.; Zanardi, E.; Ghidini, S.; Vergara, A.; Paludi, D.; Festino, A.R.; Ianieri, A. Listeria monocytogenes: Biofilms in food processing. Ital. J. Food Sci. 2012, 24, 203-213.

(C) 2018 by the authors. Licensee MDPI, Basel, Switzerland. This article is an open access article distributed under the terms and conditions of the Creative Commons Attribution (CC BY) license (http://creativecommons.org/licenses/by/4.0/). 